\title{
Significance of Co-existing Distal Radio-Ulnar Joint Injuries in the Surgical Management of Distal Radius Malunion
}

\section{Nikil Sanaba Paramesh* and Abhishek M Matapathi}

Department of Orthopaedics, Dr. B.R. Ambedkar Medical College, Bengaluru, Rajiv Gandhi University of Health Sciences, India

*Corresponding Author: Nikil Sanaba Paramesh, Department of Orthopaedics, Dr. B.R. Ambedkar Medical College, Bengaluru, Rajiv Gandhi University of Health Sciences, India.
Received: September 11, 2020

Published: October 20, 2020

(C) All rights are reserved by Nikil Sanaba

Paramesh and Abhishek M Matapathi.

\section{Abstract}

Background: Distal radius malunion is a major complication of distal radius fractures, reported in about $33 \%$ of cases. Corrective osteotomy to restore normal anatomy usually provides improved function and significant pain relief. We report the outcomes in a case-series with special attention to the potential influence of the initial management.

Material and Methods: This single-centre retrospective study included 15 patients, which included 11 males and 4 females, with a mean age of 32 years (range, 14-55 years). They were from different socio-economic and professional backgrounds. There were 10 extra-articular fractures, including 7 with volar angulation, 3 anterior marginal fractures, and 2 intra-articular T-shaped fractures; the dominant side was involved in 13/15 patients. Initial fracture management was with Kapandji intra-focal pinning in 3 patients, anterior plate in 3 patients, and non-operative reduction in 9 patients. The malunion was anterior in 13 patients, including 3 with intra-articular malunion, and posterior in 2 patients. Corrective osteotomy of the radius was performed in all 15 patients between 2018 June and 2019 July. Mean time from fracture to osteotomy was 145 days (range, 45-180 days). The defect was filled using an iliac bone graft in all patients. No procedures on the distal radio-ulnar joint were performed during the corrective osteotomy surgery. 2 patients among these underwent revision surgery on distal ulna on a later date.

Results: All 15 patients were evaluated 12 months after the corrective osteotomy. They showed gains in ranges not only of flexion/ extension, but also of pronation/supination. All patients reported improved wrist function. The flexion/extension arc increased by $44^{\circ}\left(+24^{\circ}\right.$ of flexion and $+20^{\circ}$ of extension $)$ and the pronation/supination arc by $30^{\circ}\left(+15^{\circ}\right.$ of pronation and $+15^{\circ}$ of supination $)$. Mean visual analogue scale score for pain was 1.5 (range, 0-3). Complications recorded within 12 months after corrective osteotomy were complex regional pain syndrome type I $(n=1)$, radio-carpal osteoarthritis $(n=2)$, and restricted supination due to incongruity of the distal radio-ulnar joint surfaces $(n=2)$. This last abnormality should therefore receive careful attention during the management of distal radius malunion.

Discussion: In our case-series study, 2 (13.33\%) patients required revision surgery for persistent loss of supination. Here we found that the reason was failure to perform an additional procedure on the distal radio-ulnar joint despite finding joint congruity on postoperative x-ray. Hence, it can be concluded that outcome of corrective osteotomy for distal radius malunion significantly depends on distal radio-ulnar joint congruity.

Keywords: Distal Radius Osteotomy; Ulanr Shortening; DRUJ Congruity; Unstable Radius Fractures; MDRF; Malunited Distal Radius Fracture 


\section{Abbreviations}

MDRF: Malunited Distal Radius Fractures; CT: Computed Tomography; DRUJ: Distal Radio-Ulnar Joint; VAS: Visual Analogue Scale; Fig: Figure

\section{Introduction}

Distal radius fractures are one of the most common types of fractures, accounting for around $25 \%$ of fractures in the pediatric population and up to $18 \%$ of all fractures in the elderly age group [1]. Malunion is a major complication of fractures involving the distal radius and ulna. The articular surface of the distal aspect of the radius tilts 21 degrees in the antero-posterior plane and 5 to 11 degrees in the lateral plane [2]. Traumatic dislocation of the distal radioulnar joint and injury to distal forearm are commonly encountered [3]. The incidence of MDRF (malunited distal radius fractures) appears to be greater when the fracture is treated with cast immobilization, with a historical incidence of approximately $24 \%[4,5]$. With the advent of advanced surgical techniques, the incidence of MDRF has been calculated to be as low as $11 \%$ [4]. For patients with distal radius fractures, the correct treatment determines the degree of later functional recovery. For patients with unsatisfactory reset, early surgical treatment is recommended. Delayed diagnosis and treatment often lead to chronic and persistent lower ulnar joint subluxation, dislocation, or even osteoarthritis. For patients with chronic arthritis, arthroplasty can be used to relieve pain $[6,7]$. In Indian subcontinent, due to management of fractures by Osteopaths and Quacks, the incidence of Malunion is very high. We have selected particularly the patients with restriction of functional ability for the study.

Malunion of distal radius fractures result in a fundamental change in the biomechanics of the wrist. Left untreated, this can lead to arthritis, pain, limited mobility, or dysfunction. A clinical assessment of the functional impact combined with a detailed imaging study workup allows classification of the malunion and provides an evaluation of its severity and of any alterations in joint congruity. Computed tomography (CT) contributes additional information on the condition of the cartilage and ligaments (radio-carpal, radio-ulnar, and intra-carpal), as well as on joint relationships. Corrective osteotomy of the radius, which is usually performed using the opening-wedge technique, restores normal anatomy to improve wrist function. Intra-articular malunion is particularly challenging to treat, and its outcomes are less predictable. Finally, in every case, the relationships with the distal radio-ulnar joint (DRUJ) should be evaluated after correction of the malunion, to determine whether an additional surgical procedure on the distal ulna is appropriate.

\section{Objective of the Study}

The objective of this study was to evaluate the outcomes of surgical treatment of distal radius malunion in the surgical centre.

We have used additional imaging techniques like CT to assess pre-existing Arthritic conditions and to know the status of ligaments.

\section{Materials and Methods}

A retrospective study was conducted at Dr. B.R. Ambedkar Medical College and Hospital in the department of Orthopaedics. We recorded preoperative and postoperative clinical and radiological data. The diagnosis of malunion was based on excessive anterior or posterior tilt combined with shortening of the radius. Surgery was indicated if the patient reported functional impairment and had radiological evidence of malunion.

Consecutive patients who underwent corrective osteotomy of the radius to treat distal radius malunion between 2018 June and 2019 July were included. Exclusion criteria were distal radius malunion that was not corrected or that was treated only by a surgical procedure on the DRUJ. We also excluded patients of MDRF with good wrist range of motion with no functional impairment.

Before corrective osteotomy, antero-posterior radiographs, true lateral radiographs, and CT of the wrist were obtained in all patients. Radial inclination and ulnar variance were determined on the antero-posterior radiographs and radial joint surface obliquity on the lateral radiograph (Table 1). None of the imaging studies obtained before corrective osteotomy showed evidence of osteoarthritis.

\begin{tabular}{|l|c|c|c|c|}
\hline & Number & $\begin{array}{c}\text { Ulnar variance } \\
\text { (mm) }\end{array}$ & $\begin{array}{c}\text { Radial inclination } \\
\text { (degree) }\end{array}$ & $\begin{array}{c}\text { Distal radial joint surface } \\
\text { obliquity (degree) }\end{array}$ \\
\hline $\begin{array}{l}\text { Volarly angulated } \\
\text { malunion }\end{array}$ & 12 & $+5(+7$ to +3$)$ & $25^{\circ}\left(23^{\circ}\right.$ to $\left.27^{\circ}\right)$ & $+30^{\circ}\left(+28^{\circ}\right.$ to $\left.+32^{\circ}\right)$ \\
\hline $\begin{array}{l}\text { Dorsally angulated } \\
\text { malunion }\end{array}$ & 3 & $+4(+6$ to +1$)$ & $24^{\circ}\left(22^{\circ}\right.$ to $\left.26^{\circ}\right)$ & $-35^{\circ}\left(-30^{\circ}\right.$ to $\left.-40^{\circ}\right)$ \\
\hline
\end{tabular}

Table 1: Computed tomography measurements on the 15 distal radius fracture malunions (mean values). 
Operative technique

The procedures were performed under General and Regional Anesthesia. According to this review volar approach is more easier and popular due it's minor complication than dorsal approach and can be used in volar or dorsal displacement of malunited fracture distal radius by volar angle fixed plate. Moreover, a volar approach is easier than a dorsal approach and the reduction of the volar cortex is simple because of less comminution and the advantage of direct vision [8].

\section{Volarly angulated malunion $(\mathrm{n}=12)$}

Volar approach of Henry was used in all 12 patients. The flexor tendons and median nerve were identified and reflected. The pronator quadratus muscle was incised longitudinally and elevated from the volar aspect of the radius. The malunion site was identified with fluroscopy. A saw was then used to perform a transverse bone cut and posterior hinge was left intact. The cut was opened by placing a Meary spreader and the correction was checked by fluoroscopy. The goal was to obtain $10^{\circ}$ of forward tilt of the radial joint surface. The defect created by the osteotomy was filled with a bone graft of iliac cortical and cancellous bone. The osteotomy site and graft were then stabilised by implanting a Volar Locking Plate. In 4 patients where the osteotomy extended to the intra-articular compartment Variable angle Locking plates were used. No procedures were performed on the head of the ulna in the primary procedure.

Dorsally angulated malunion $(\mathrm{n}=3)$

We have used dual approach i.e. either Volar or Dorsal approach to the malunion based on fracture configuration. Volar approach was as described above. The dorsal approach has been described subsequently.

Dorsal longitudinal incision was made between the radial and ulnar styloid process. The dorsal retinaculum was incised longitudinally. Extensor pollicis longus tendon is retracted radially and dissection continued between the third and fourth compartments. Two parallel pins were implanted to identify the fracture site and to guide the transverse osteotomy performed using a saw. A Meary spreader was used to correct the deformity by inducing $10^{\circ}$ of forward tilt of the radial joint surface. A graft composed of iliac cortical and cancellous bone was implanted to fill the defect. Fixation was with a dedicated dorsal plate after resection of Lister's tubercle. The extensor retinaculum was placed beneath the extensor tendons to protect them from the underlying plate. No procedure on the head of the ulna was performed.

\section{Postoperative management}

Forearm was immobilized with POP Slab. After 6weeks slab was removed and radiographs were then taken to check that the osteotomy site had healed. The slab was then removed and a rehabilitation programme followed for 2 months on average (range, 1 - 3 months).

\section{Assessment methods}

The clinical evaluation relied on the visual analogue scale (VAS) pain score and goniometer measurements of wrist flexion/extension and pronation/supination. We were able to contact 13 of the 15 patients, who completed the Quick-DASH questionnaire [9] after a mean follow-up of 18months (range, 12 - 24 months).

Antero-posterior and lateral radiographs of the treated wrist in the neutral position were obtained immediately after surgery then every 3 months. Radial inclination, ulnar variance, and radial joint surface obliquity were measured on the radiographs. The radiographs were examined for signs of osteoarthritis, which was classified according to Knirk and Jupiter [10].

Mean preoperative and postoperative values of continuous wrist motion variables were compared using the non-parametric MannWhitney test.

\section{Results and Discussion}

All the patients underwent corrective osteotomy within 6 months of the fracture, i.e. after a mean interval of 145 days. Follow-up was at least 12 months in all patients.

Mean patient age at the time of the fracture was 32 years (range, 14 - 60 years). The dominant side was involved in 13 patients. Of the 15 fractures, 10 were extra-articular, 3 anterior marginal, and 2 intra-articular $\mathrm{T}$ shaped fractures. Distal radial joint surface tilt was dorsal in 3 patients and volar in 12 patients. Other fractures, found in 2 patients, involved the styloid process of the ulna $(n=2)$. The initial treatment consisted of Kapandji intra-focal pinning in 3 patients, volar plate fixation in 3 patients, and non-operative management in 9 patients. Table 2 lists the main characteristics of the fractures and treatment methods. The malunion was volarly angulated in 12 patients, including 5 with intra-articular involvement, and dorsally angulated in 3 patients (Figure 1). 


\begin{tabular}{|l|c|c|}
\hline 10 extra-articular fractures & $\mathbf{7}$ volarly angulated & 3 dorsally angulated \\
\hline Initial treatment & $\begin{array}{c}\text { Kapandji pinning, } \mathrm{n}=2 \\
\text { Non-operative treatment, } \mathrm{n}=5\end{array}$ & $\begin{array}{c}\text { Kapandji pinning, } \mathrm{n}=1 \\
\text { Non-operative treatment, } \mathrm{n}=2\end{array}$ \\
\hline 3 anterior marginal fractures & 3 volarly angulated & \\
\hline Initial treatment & $\begin{array}{c}\text { Plate }+ \text { pin fixation, } \mathrm{n}=2 \\
\text { Non-operative treatment, } \mathrm{n}=1\end{array}$ & \\
\hline 2 intra-articular Tshaped fractures & $\begin{array}{c}2 \text { volarly angulated } \\
\text { Initial treatment }\end{array}$ & $\begin{array}{c}\text { Plate + pin fixation, } \mathrm{n}=1 \\
\text { Non-operative treatment, } \mathrm{n}=1\end{array}$ \\
\hline
\end{tabular}

Table 2: Main characteristics of the fractures and initial treatment in the 12 study patients.

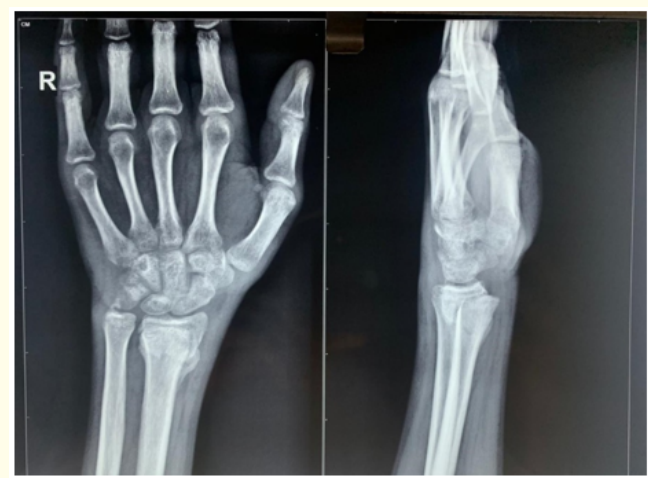

Figure 1: Example of an extra-articular fracture with dorsal angulation managed conservatively by an Osteopath.

The main patient complaint was restricted pronation and supination, followed by pain. With the elbow flexed, mean motion ranges measured by goniometry before osteotomy were as follows: flexion, $36^{\circ}\left(10^{\circ}\right.$ to $\left.55^{\circ}\right)$; extension, $42^{\circ}\left(15^{\circ}\right.$ to $\left.55^{\circ}\right)$; pronation, $53^{\circ}\left(35^{\circ}\right.$ to $\left.80^{\circ}\right)$; and supination, $28^{\circ}\left(0^{\circ}\right.$ to $\left.60^{\circ}\right)$. The mean VAS pain score was 2.8 (range, 1 - 5).

\section{Clinical outcomes}

Patients consistently reported improved wrist motion and function 12 months after corrective osteotomy. Of the 15 patients, 11 were satisfied or very satisfied with the procedure. The mean VAS pain score was 1.5 (range, 0 - 3) and the mean Quick-DASH score was 21.6 (range, 12 - 48).

Table 3 compares pain during wrist motion and wrist motion ranges before and after corrective osteotomy. The flexion/extension arc increased by $44^{\circ}\left(+24^{\circ}\right.$ of flexion and $+20^{\circ}$ of extension $)$ and the pronation/supination arc by $30^{\circ}\left(+15^{\circ}\right.$ of pronation and $+15^{\circ}$ of supination).

\section{Radiological outcomes}

Immediate post-operative radiograph was assessed in all patients (Figure 2). Progressive radio-carpal osteoarthritis developed in 2 patients. The osteoarthritis stage according to the Knirk and Jupiter classification was 1 in 1 patient and 2 in 1 patient [10].

\begin{tabular}{|l|c|c|}
\hline & Pre surgical & Post surgical \\
\hline Flexion & $36^{\circ}\left(10^{\circ}\right.$ to $\left.50^{\circ}\right)$ & $60^{\circ}\left(15^{\circ}\right.$ to $\left.70^{\circ}\right)$ \\
\hline Extension & $42^{\circ}\left(15^{\circ}\right.$ to $\left.55^{\circ}\right)$ & $62^{\circ}\left(30^{\circ}\right.$ to $\left.75^{\circ}\right)$ \\
\hline Pronation & $53^{\circ}\left(35^{\circ}\right.$ to $\left.80^{\circ}\right)$ & $68^{\circ}\left(40^{\circ}\right.$ to $\left.82^{\circ}\right)$ \\
\hline Supination & $28^{\circ}\left(0^{\circ}\right.$ to $\left.60^{\circ}\right)$ & $43^{\circ}\left(15^{\circ}\right.$ to $\left.60^{\circ}\right)$ \\
\hline Pain (VAS score) & $3(2-5)$ & $2(0-3)$ \\
\hline $\begin{array}{l}\text { Functionality (Quick } \\
\text { DASH) }\end{array}$ & - & $21(12-48)$ \\
\hline
\end{tabular}

Table 3: Clinical outcomes after 12 months in 15 patients (mean values).

Mean ulnar variance was -1.8 (range, -9 to +2 ), mean radial inclination was $20.75^{\circ}$ (range, $14^{\circ}$ to $32^{\circ}$ ), and mean radial joint surface obliquity was $-3.5^{\circ}$ (range, $-28^{\circ}$ to $22^{\circ}$ ). Table 4 compares preoperative and postoperative radiographic values. Persistent posterior tilt was noted in the patients with posterior malunion. All grafts showed good uptake with no complications.
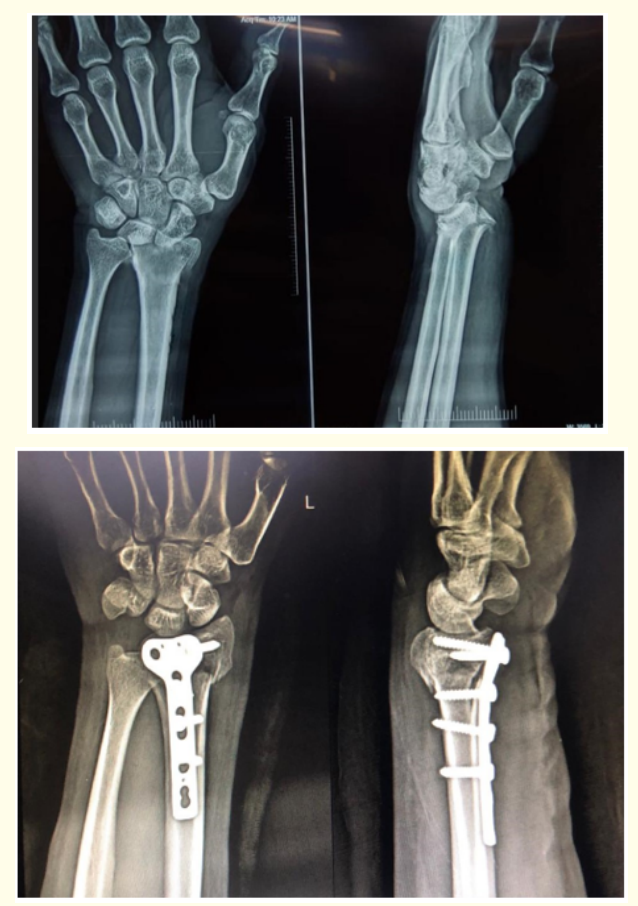

Figure 2: Pre- operative and post-operative day1 radiographs of a dorsally angulated fracture fixed with volar plate. 


\begin{tabular}{|l|c|c|c|c|c|c|}
\hline & \multicolumn{2}{|c|}{ Ulnar variance (mm) } & \multicolumn{2}{c|}{ Radial inclination (degree) } & \multicolumn{2}{c|}{ Distal radial joint surface obliquity (degree) } \\
\hline & Preop & Postop & Preop & Postop & Preop & Postop \\
\hline 10 anterior malunions & $\begin{array}{c}+6 \\
(+8 \text { to }+3)\end{array}$ & $\begin{array}{c}-2 \\
(-5 \text { to }+3)\end{array}$ & $\begin{array}{c}25^{\circ} \\
\left(23^{\circ} \text { to } 27^{\circ}\right)\end{array}$ & $\begin{array}{c}23^{\circ} \\
\left(14^{\circ} \text { to } 31^{\circ}\right)\end{array}$ & $\begin{array}{c}30^{\circ} \\
\left(+28^{\circ} \text { to }+33^{\circ}\right)\end{array}$ & $\begin{array}{c}+10^{\circ} \\
\left(-4^{\circ} \text { to } 22^{\circ}\right)\end{array}$ \\
\hline $\begin{array}{c}+4 \\
2 \text { posterior malunions } \\
(+5 \text { to }+1)\end{array}$ & $\begin{array}{c}-1 \\
(-9 \text { to }+2)\end{array}$ & $\begin{array}{c}24^{\circ} \\
\left(21^{\circ} \text { to } 26^{\circ}\right)\end{array}$ & $\begin{array}{c}18^{\circ} \\
\left(15^{\circ} \text { to } 25^{\circ}\right)\end{array}$ & $\begin{array}{c}-27^{\circ} \\
\left(-20^{\circ} \text { to }-40^{\circ}\right)\end{array}$ & $\begin{array}{c}-16^{\circ} \\
\left(-30^{\circ} \text { to }+10^{\circ}\right)\end{array}$ \\
\hline
\end{tabular}

Table 4: Radiological outcomes after 24 months in the 12 study patients (mean values).

Complications and revisions

Complex regional pain syndrome type I developed in 1 patient during the 18 months following corrective osteotomy. In 2 patients, the range of supination was limited (mean, $7^{\circ}$ ). Pre-operative Xray of these patients showed ulnar variance of +12 and +8 . In 1 of these patients there was dorsal subluxation of the ulnar head. Both these patients required resection-stabilisation of the distal ulna
[11] after 1 years after corrective osteotomy. Table 5 shows the preoperative and postoperative radiological data of these 2 patients.

Osteoarthritis of the radio-scaphoid joint developed after corrective osteotomy in 2 patients with intra-articular fractures. We have so far not encountered any recurrent symptoms for these patients with osteoarthritis wrist. Hence conservative management with medications has been administered to the arthritic patients.

\begin{tabular}{|c|c|c|c|c|}
\hline & Type of fracture & $\begin{array}{l}\text { Angles before oste- } \\
\text { otomy }\end{array}$ & Type of osteotomy & $\begin{array}{l}\text { Angles after } \\
\text { osteotomy }\end{array}$ \\
\hline Patient \#1 & Dorsal angulation & $\begin{array}{c}\mathrm{UV}+2 \\
\mathrm{RI} 22^{\circ} \\
\text { Anteversion } 20^{\circ}\end{array}$ & $\begin{array}{l}\text { Anterior, bone sub- } \\
\text { stitute }\end{array}$ & $\begin{array}{c}\mathrm{RU}+3 \\
\mathrm{RI} 32^{\circ} \\
\text { Retroversion } 11^{\circ}\end{array}$ \\
\hline Patient \#2 & $\begin{array}{l}\text { T-shaped intra-articular fracture with } \\
\text { volar angulation }\end{array}$ & $\begin{array}{c}\text { RU } 0 \\
\text { RI } 24 \\
\text { Retroversion } 28^{\circ}\end{array}$ & $\begin{array}{l}\text { Posterior, iliac bone } \\
\text { graft }\end{array}$ & $\begin{array}{c}\mathrm{RU}+2 \\
\text { Retroversion } 30^{\circ}\end{array}$ \\
\hline
\end{tabular}

Table 5: Preoperative and postoperative data in the 2 patients who underwent revision surgery with distal radio-ulnar joint resectionstabilisation within 2 years after corrective osteotomy.

RI: Radial Inclination; UV: Ulnar Variance.

No cases of infection or non-union were recorded. No complications related to iliac graft harvesting were observed. Neither was there any complications related to plate fixation, and none of the plates were removed within 2 years after corrective osteotomy.

\section{Discussion}

A.I. Kapandji described a procedure for closed pinning of the distal radius fracture which is a commonly followed procedure for extra-articular fractures of the distal radius [12]. However, clinical studies of this Kapandji method displayed a relatively high rate of secondary displacements in up to $10 \%$ of the cases $[13][14,15]$. A study in 2000, reported secondary displacement in $30 \%$ of cases inspite of 6 weeks of immobilization [16]. Another study in 2012, reported a reduction in the incidence of secondary displacement since the introduction of volar plate fixation [17]. In our study, 3 out of the 15 patients were initially managed by kapandji pinning. All 3 originally had dorsally displaced extra-articular fractures. Post Kapandji pinning 2 of these had resulted in volarly angulated malunion and 1 had persistent dorsally angulated malunion. On reviewing the post-operative radiographs taken 7 days after initial surgery, it showed excessive reduction in the former 2 patients and inadequate reduction in the latter 1 patient.

The final functional outcome depends on the anatomic restoration of the distal radius and DRUJ. A study in 1997, on cadaveric MDRF model, found that $10 \mathrm{~mm}$ of loss of radial height led to substantial loss of supination (29\%) and pronation (47\%) [18]. It also showed that $5 \mathrm{~mm}$ of ulnar translation of the radial epiphysis resulted in a mean pronation loss of $23 \%$ [18]. 
Another component of the malunion which wasn't studied extensively initially was the rotation. A study in 2005, described specific features of anterior malunions emphasizing on limitation of volar angulation by the strong anterior capsular plane with minimal shortening of the radius and pronation of the distal fragment which caused incongruity of the DRUJ with a marked decrease in the range of supination [19]. In a study conducted at Bristol, 26 of the 35 subjects (74\%) in the distal radius fracture study group had a rotational deformity [20]. Similar findings were found in a German study, which noted this rotational deformity in 23 of 37 malunions. Rotational deformity was found to be more common in volar malunions. The wrist function seemed to be better in dorsal malunion [21]. In our study, even after postoperative radiological angles were within the normal range, the mean increase in supination was only $7^{\circ}$ in the 10 patients with anterior malunion, after exclusion of the 2 patients who underwent revision surgery. This limited improvement maybe ascribed to the uncorrected rotational component of the radial malunion thereby indicating that restoration of just the ulnar variance did not ensure good DRUJ congruity. Thus there is a need to correct even the rotational deformities in addition to the volar or dorsal deformities thereby making the procedure more challenging.

The study in 2005, showed that optimal results were gained by combined distal radius osteotomy and procedure on head of ulna when compared to isolated osteotomy of Radius [19]. In our study, all 15 patients were operated with isolated osteotomy of distal radius and 2 of them required revision surgery for persistent restriction of rotation. On analyzing the pre-operative and postosteotomy radiographs it was noted that ulnar variance had not been corrected. This could have been effectively averted by identifying the need for a procedure on ulnar head along with the radial osteotomy through detailed evaluation of pre-operative range of motion and radiological studies. These findings are in accordance with other similar studies which infer that corrective osteotomy for MDRF should include restoration of DRUJ congruity and a procedure on DRUJ must be performed when there is persistent limitation of Pronation-Supination arc intra-operatively [19,22].

A study in 2011 reported that if ulnar variance was more than $+10 \mathrm{~mm}$ preoperatively then the radial osteotomy alone could not restore the DRUJ congruity. In such cases decision of conservative or radical treatment can be made with the help of pre-operative computed arthro-tomography. If the joint surface is intact, conservative surgery with stabilization and/or ulnar shortening can be considered. However, lesions involving the joint may require a radical approach [23]. We experienced similar situation in 2 of our patients who had ulnar variance of +12 and +8 . Modified Darrach's procedure for distal ulna resection, as described by Mansat., et al. [11], was carried out on these 2 of our patients with severe restricted pronation/supination arc. This resulted in significant increase in the arc by achieving a mean increase in pronation by $+17^{\circ}$ and supination by $+43^{\circ}$ thus achieving the functional requirements of the patients.

A study in 2001, showed bone graft donor site complication rate of $31 \%$ [24]. In our study, bone graft was used in all 15 patients with no donor site complications. In the study of 2005, a procedure was described for MDRF with lateral approach posterior to the first extensor compartment where brachioradialis muscle was reflected from posterior to anterior to approach the radius. This provided a better control over the distal fragment and helped in better reduction in pronation. Cylindrical osteotomy was performed in sagittal plane. This restored the radial length without the requirement of bone graft as there was no shortening. In doing so, they used graft in only 3 patients [19]. In our study, we used the standard dorsal and Henry's volar approach and required bone graft for all 15 cases. In another study, an antero-lateral approach was described where the radial artery, brachioradialis and first extensor compartment is detached anterior to posterior for distal radius [25]. This not only provided the better control for rotational correction but also allowed graft harvesting from the operative site thereby avoiding the donor site complications [24]. All our bone grafts were harvested from the patients' iliac crest.

In a technique described in 1991, Biplanar closing-wedge osteotomy was performed avoiding the morbidity of bone graft harvesting [26]. However, it has to be combined with Darrach's procedure to correct for the loss of radial length [26,27]. In the 2 patients with posterior malunion, 1 of them was managed by volar approach of Henry with closed wedge osteotomy and iliac bone graft for filling an isolated defect in lateral column, as there was not much impaction or shortening. The other patient was operated via dorsal approach with open wedge osteotomy and iliac bone graft.

The functional outcome also depends on carpal bone stability which can be altered by radial malunion [28]. A study conducted in 2002 reported that the radio-lunate flexion angle could help differentiate between radio-carpal and mid-carpal malalignment [29]. In our study, the radiolunate angle was more than $25^{\circ}$ in 10 patients 
whereas it was less than or equal to $25^{\circ}$ in 5 patients indicating mid-carpal instability and radio-carpal instability respectively. Post radial osteotomy, the radiolunate angle was rectified in $12 \mathrm{pa}$ tients and remained higer than $25^{\circ}$ in the other 3 patients.

\section{Conclusion}

The primary goal of correction of distal radius malunions after surgery is restoration of the normal anatomy thereby achieving improved wrist range of motion and reduction of pain. In our study, we found that the wrist range of motion, particularly supination, was not restored sufficiently with just transverse osteotomy. To achieve best clinical and radiological outcomes, rotational component of the malunion must also be corrected in distal radius osteotomy. Additionally, ulnar surgery to restore DRUJ anatomy is required in some cases to improve the postoperative functional outcomes.

\section{Disclosure of Interest}

The authors declare that they have no competing interest.

\section{Bibliography}

1. Nellans Kate W., et al. "The epidemiology of distal radius fractures". Hand Clinics 28.2 (2012): 113-125.

2. Trumble Thomas E., et al. "Instructional course lectures, the American academy of orthopaedic surgeons - intra-articular fractures of the distal aspect of the radius*'”. The Journal of Bone and Joint Surgery 80.4 (1998): 582-600.

3. George Albert V and Jeffrey N Lawton. "Management of complications of forearm fractures". Hand Clinics 31.2 (2015): 217-233.

4. B J McGrory and P C Amadio. "Malunion of the distal radius". in: Cooney WP, Linscheid RL, Dobyns JH, eds. The Wrist: Diagnosis and Operative Treatment. St Louis, MO: Mosby (1998): 356-384.

5. Sharma, Himanshu., et al. "Outcomes and complications of fractures of distal radius (AO Type B And C): volar plating versus nonoperative treatment". Journal of Orthopaedic Science 19.4 (2014): 537-544.

6. Crosby Carla A., et al. "Rehabilitation Following Thumb CMC, Radiocarpal, And DRUJ Arthroplasty". Hand Clinics 29.1 (2013): 123-142.

7. Degreef Ilse and Luc De Smet. "The Scheker distal radioulnar joint arthroplasty to unravel a virtually unsolvable problem". Acta orthopaedica Belgica 79.2 (2013): 141-145.
8. Oka Kunihiro., et al. "A Comparison Of Corrective Osteotomies Using Dorsal And Volar Fixation For Malunited Distal Radius Fractures". International Orthopaedics 42.12 (2018): 28732879.

9. Dubert T., et al. "Le Questionnaire DASH. Adaptation Française D’un Outil D'évaluation International". Chirurgie De La Main 20.4 (2001): 294-302.

10. J L Knirk and J B Jupiter. "Intra-Articular Fractures Of The Distal End Of The Radius In Young Adults". The Journal of Bone and Joint Surgery 68.5 (1986): 647-659.

11. P Mansat., et al. "Long-Term Outcome Of Distal Ulna ResectionStabilisation Procedures In Post-Traumatic Radio-Ulnar Joint Disorders". Orthopaedics and Traumatology: Surgery and Research 96.3 (2010): 216-221.

12. A I Kapandji. "Treatment Of Distal Radius Fractures By IntraFocal Pinning With Arum Pins". Wrist Disorders (1992): 217225.

13. Kerboul B., et al. "Étude comparative de trois methodes therapeutiques de la fracture de Pouteau-Colles. A propos des 97 cas". Journal de Chirurgie 123 (1986): 428-434.

14. Lecestre P., et al. "Fractures de l'extremité inferieure du radius traitées par la methode de Kapandji. Analyse de 100 cas". Annales de Chirurgie 42 (1988): 756-769.

15. P Y Milliez., et al. "Influence de la mobilisation precoce après embrochage intra-focal selon Kapandji dans les fractures de l'extremité inferieure du radius. Resultats d'une étude prospective sur 60 cas". International Orthopaedics 16 (1992): 3943.

16. G Herzberg and C Dumontier. "Symposium: les fractures fraiches du radius distal chez l'adulte". Revue de Chirurgie Orthopédique et Réparatrice de l Appareil Moteur 86.1 (2000): 1585-1588.

17. L Obert., et al. "Fixation Of Distal Radius Fractures In Adults: A Review". Orthopaedics and Traumatology: Surgery and Research 99.2 (2013): 216-234.

18. Bronstein Andrew J., et al. "The effects of distal radius fracture malalignment on forearm rotation: a cadaveric study". The Journal of Hand Surgery 22.2 (1997): 258-262.

19. P Saffar and Y Tafnkji. "Cal vicieux du radius en flexion". Chirurgie de la Main 24 (2005): 299-304.

20. Filer J., et al. "Assessing Distal Radius Malrotation Following Fracture Using Computed Tomography". Journal of Orthopaedic Surgery 27.3 (2019): 1-6. 
21. KJ Prommersberger., et al. "Rotational deformity in malunited fractures of the distal radius". The Journal of Hand Surgery 29.1 (2004): 110-115.

22. J Van Cauwelaert and L De Smet. "Corrective Osteotomy For Malunion Of The Distal Radius In Young And Middle-Aged Patients: An Outcome Study". Chirurgie De La Main 22.2 (2003): 84-89.

23. B Coulet., et al. "Is Distal Ulna resection influential on outcomes of distal radius malunion corrective Osteotomies?". Orthopaedics and Traumatology: Surgery and Research 97.5 (2011): 479-488.

24. Gupta NR., et al. "Perioperative and long-term complications of iliac crest bone graft harvesting for spinal surgery: a quantitative review of literature". International Medical Journal 8 (2001): 163-166.

25. P Mathew and M G Elias. "Anterolateral Surgical Approach To The Malunited Distal Radius Fracture For Corrective Osteotomy And Bone-Graft Harvest". Techniques in Hand and Upper Extremity Surgery 17.1 (2013): 28-34.

26. M A Posner and L Ambrose. "Malunited Colles' Fractures: Correction With A Biplanar Closing Wedge Osteotomy". The Journal of Hand Surgery 16.6 (1991): 1017-1026.

27. G Sennwald., et al. "Le cal vicieux du radius distal et son traitement: à propos de 122 radius". International Orthopaedics 16 (1992): 45-51.

28. DR Bickerstaff and MJ Bell “Carpal Malalignment In Colles' Fractures". The Journal of Hand Surgery: Journal of the British Society for Surgery of the Hand 14.2 (1989): 155-160.

29. A Gupta., et al. "Carpal Alignment In Distal Radial Fractures". BMC Musculoskeletal Disorders 3.1 (2002).

\section{Assets from publication with us}

- Prompt Acknowledgement after receiving the article

- Thorough Double blinded peer review

- Rapid Publication

- Issue of Publication Certificate

- High visibility of your Published work

Website: https://www.actascientific.com/

Submit Article: https://www.actascientific.com/submission.php

Email us: editor@actascientific.com

Contact us: +919182824667

Citation: Nikil Sanaba Paramesh and Abhishek M Matapathi. "Significance of Co-existing Distal Radio-Ulnar Joint Injuries in the Surgical Management of Distal Radius Malunion". Acta Scientific Orthopaedics 3.11 (2020): 50-57. 